\title{
Calibration of a frequency-domain reflectometer for determining soil-water content in a clay loam soil
}

\author{
G Lukanu and MJ Savage* \\ Soil-Plant-Atmosphere Continuum Research Unit, School of Environmental Sciences, University of KwaZulu-Natal, \\ Pietermaritzburg, South Africa
}

\begin{abstract}
A soil-water frequency domain reflectometry sensor, the ThetaProbe, was evaluated for its ability to measure the apparent soil dielectric constant and subsequent estimation of soil-water content. The soil-water content of a clay-loam soil, determined using factory-supplied parameters for the sensor and soil-estimated parameters, was compared to the soil-water content determined in the laboratory. The range in soil-water content was from 0.20 to $0.42 \mathrm{~m}^{3} \cdot \mathrm{m}^{-3}$. A total of 78 soil samples from the 0 to $600 \mathrm{~mm}$ depth of a clay loam soil were used for these comparisons. There was a good correlation between sensor soil-water content determined using the factory-supplied parameters and the gravimetric soil-water content. Use of both the factorysupplied and the soil-estimated parameters resulted in more than $20 \%$ overestimation of soil-water content compared to the gravimetric soil-water content. However, using a recalibration process, the adjusted soil-water content was within $0.02 \mathrm{~m}^{3} \cdot \mathrm{m}^{-3}$ for both the factory-supplied and the soil-estimated calibration constants. Soil bulk density, clay content and temperature had negligible influence on sensor soil-water contents.
\end{abstract}

Keywords: soil-water content, ThetaProbe, frequency domain reflectometer

\section{Introduction}

Knowledge of soil-water content is important for water management and hydrological studies and for calibration and validation of soil-water balance models. Monitoring soil-water content for irrigation scheduling, based on a measurement and control system, requires fast, precise, non-destructive and in situ measurement techniques (Lukangu et al., 1999; Gebregiorgis and Savage, 2006a, b). The laboratory methods for determining soil-water content gravimetrically and pressure plate soil-water potential fail to satisfy this requirement, although they are still used for calibration purposes. The neutron probe field method has the advantage of allowing measurements of soil-water content for a greater soil volume but radioactive hazard, lack of automated data collection methodology, and high cost restrict its use.

Dielectric-based soil-water content techniques are influenced by factors that affect the dielectric constant of the soil other than water. The time domain reflectometry (TDR) method involves measuring the propagation of an electromagnetic pulse along the transmission lines (wave guides). By measuring the travel time, the velocity and hence the apparent dielectric constant of the soil can be estimated. Usually, the TDR method is not soilspecific (Drnevich et al., 2005), and therefore no soil calibration is required. The frequency-domain reflectometer (FDR) method used in the present study makes use of radio frequencies and the electrical capacitance of a capacitor (formed by using the soil and embedded rods as a dielectric) for determining the dielectric constant and thus the soil water content. The signal reflected

\footnotetext{
* To whom all correspondence should be addressed.

im +27332605510 ; fax: +27332605514 ;

e-mail: savage@ukzn.ac.za

Received 21 January 2005; accepted in revised form 1 November 2005
}

by soil combines with the generated signal to form a standing wave with amplitude that is a measure of the soil-water content. In the case of capacitance-type sensors, such as that used by Grooves and Rose (2004), the charge time of a capacitor is used to determine the soil-water content. Profile-probe versions using FDR and capacitance methods are now commercially available (Whalley et al., 2004; Czarnomski et al., 2005; Mwale et al., 2005).

The effect of clay, soil organic matter content and soil bulk density on TDR measurements has been reported by Topp et al. (1980), Roth et al. (1990), and Jacobson and Schjonning (1993a, b). A temperature effect has been reported by Topp et al. (1980) while an iron influence on the dielectric constant has been discussed by Robinson et al. (1994). Evett et al. (2005) found that TDR measurements may be affected by soil salinity, soil temperature, clay type and clay content. The TDR technique may overestimate soil-water content in saline soils because the apparent dielectric constant also depends on the electrical conductivity of the soil (Wyseure et al., 1997). For example, Wyseure et al. (1997) used a dielectric-based technique to estimate the electrical conductivity. Miyamoto and Maruyama (2004) found that by coating the TDR rods, more accurate measurements in a heavily fertilised paddy field was possible. Roots, earthworm channels, cracks and stones can also cause small variations in soil-water content estimated using the dielectric-based technique (Jacobson and Schjonning 1993b). Furthermore, old root channels would affect dielectric measurements if these were within the measurement volume of the sensor.

The objective of this work was firstly to calibrate the FDR sensors, for example, the ThetaProbe, for the site and compare the calibration parameters with those supplied by the manufacturer. A second objective was to evaluate the effect of soil bulk density, clay content and temperature on soil-water content measured with these sensors. 


\section{Materials and methods}

The ML1 ThetaProbe (Delta-T Devices, Cambridge, England), as well as so-called TDR and other FDR techniques can provide a continual, precise, non-destructive and in situ measurement of soil-water content under field conditions.

\section{Theoretical considerations}

The ThetaProbe (type ML1) is essentially an FDR sensor that detects the ratio between the oscillator voltage (for $100 \mathrm{MHz}$ signal) and that reflected by rods installed in soil. The ratio of the two voltages is dependent essentially on the apparent dielectric constant of the soil $(\varepsilon)$ which is determined by the soil-water content. A $5^{\text {th }}$ order polynomial of the sensor analogue output voltage $\mathrm{V}$ (in volts), is used to estimate the square root of the dielectric constant of the soil $(\sqrt{ } \varepsilon)$ as (Delta-T Devices, 1999):

$$
\sqrt{ } \varepsilon=1+6.19 \mathrm{~V}-9.72 \mathrm{~V}^{2}+24.35 \mathrm{~V}^{3}-30.84 \mathrm{~V}^{4}+14.73 \mathrm{~V}^{5}
$$

The volumetric soil-water content $\theta_{\mathrm{v}}\left(\mathrm{m}^{3} \cdot \mathrm{m}^{-3}\right)$ is calculated from the dielectric constant by using the soil calibration constants $a_{\text {o }}$ and $a_{1}$ :

$$
\theta_{\mathrm{v}}=\left(\sqrt{ } \varepsilon-a_{\mathrm{o}}\right) / a_{1}
$$

where:

$a_{\mathrm{o}}$ is the square root of the dielectric constant of dry soil

$\left(\sqrt{ } \varepsilon_{0}\right)$ where $\varepsilon_{0}$ is the dielectric constant for dry soil) calculated using the corresponding measured voltage output and Eq. (1)

$a_{1}$ is the difference between the square root of the dielectric constant of saturated $\left(\sqrt{ } \varepsilon_{w}\right)$ and that for dry soil divided by soil-water content at saturation $\left(\theta_{\mathrm{vs}}\right)$ :

$$
a_{1}=\left(\sqrt{ } \varepsilon_{w}-\sqrt{ } \varepsilon_{0}-\right) / \theta_{\mathrm{vs}}
$$

The square root of the dielectric constant of the soil at saturation is also calculated using Eq. (1) for the corresponding measured voltage output. Factory values for $a_{0}$ and $a_{1}$ of 1.6 and 8.4 for mineral soils and 1.3 and 7.8 for organic soils are used, respectively. These values were derived from measurements in many different soil types.

The calibration process is a tool to minimise the error that an inaccurate sensor would cause in the observed data. Statistical equations by Snedecor and Cochran (1980) provide a method for estimating an independent variable $X$ (laboratory soil-water content) from dependent variable $Y$ (sensor soil-water content), referred to as a prediction of $X$ from $Y$, from a $Y v s . X$ relationship having a slope $b$ and intercept $I$ :

$$
X=[(Y-I) / b] /\left(1-c^{2}\right)
$$

where:

$$
c^{2}=\left(1 / \sum x^{2}\right)\left(t S_{y \cdot x} / b\right)^{2}
$$

is a factor that accounts for the error in estimating $X$ using the dependent variable $Y$, slope $b$ and intercept $I$ (where $x=X-\bar{X}), t$ is the Student $t$ statistic $S_{y . x}$ is the standard error of $Y$ on $X$ ). For perfect agreement between the laboratory $(X)$ and sensor soilwater contents $(Y), c^{2}=0$ and hence $X=(Y-I) / b$.

\section{Experimental procedure}

Five ThetaProbe sensors were calibrated in the laboratory using clay loam soil from Vita Farm, Tala Valley, KwaZuluNatal, South Africa (latitude $\approx 29^{\circ} 50^{\prime}$ S, longitude $\approx 30^{\circ} 30^{\prime} \mathrm{E}$ and altitude $\approx 900 \mathrm{~m}$ ). The sensor is $125 \mathrm{~mm}$ long and $40 \mathrm{~mm}$ in diameter with a cylinder housing the electronics, with four sensing rods $60 \mathrm{~mm}$ in length, with three of the rods distributed uniformly around a circumference of $26.5 \mathrm{~mm}$ and one rod at the centre.

Soil bulk density was determined using a core method (Blake and Hartge, 1986). Undisturbed soil cores, with a diameter of $100 \mathrm{~mm}$ and a thickness of $80 \mathrm{~mm}$ were taken from each of four $150-\mathrm{mm}$ layers at the field site (Table 1). The soil samples were covered, transported to the laboratory, and soil-water content measured using a sensor inserted into the soil sample. The sensor was then removed and the samples were weighed. The samples were then oven-dried for $24 \mathrm{~h}$ at $105^{\circ} \mathrm{C}$ and the gravimetric soil-water content calculated. The volumetric soil-water content $\left(\theta_{\mathrm{v}}\right)$ of the core was calculated from the gravimetric soilwater content and soil bulk density. This procedure was repeated for all 78 soil samples. Particle size distribution was determined using the pipette method reported by Gee and Bauder (1986).

Sensors were connected to a CR7X data-logger (Campbell Scientific Inc., Logan, Utah) and sensed using a differential voltage instruction. Volumetric soil-water content was estimated from the measured voltages using Eq. (2). The $a_{\mathrm{o}}$ and $a_{1}$ values therefore allowed the real-time estimation of soil-water content

\begin{tabular}{|c|c|c|c|c|c|c|c|c|c|}
\hline \multicolumn{10}{|c|}{$\begin{array}{c}\text { TABLE } 1 \\
\begin{array}{c}\text { Physical characteristics of four strata of the soil studied } \\
\text { (Lukangu et al., 1999) }\end{array}\end{array}$} \\
\hline \multirow[t]{2}{*}{$\begin{array}{l}\text { Depth } \\
\text { mm }\end{array}$} & \multirow[t]{2}{*}{$\begin{array}{l}\text { Bulk } \\
\text { density } \\
\mathrm{kg} \mathrm{m}^{-3}\end{array}$} & \multicolumn{3}{|c|}{$\begin{array}{l}\text { Soil-water content }\left(\mathrm{m}^{3} \cdot \mathrm{m}^{-3}\right) \\
\text { for various depths and } \\
\text { matric potentials }\end{array}$} & \multicolumn{3}{|c|}{$\begin{array}{l}\text { Particle size } \\
\text { distribution }\end{array}$} & \multirow[t]{2}{*}{$\begin{array}{c}\text { Gravel } \\
\%\end{array}$} & \multirow[t]{2}{*}{$\begin{array}{c}\text { Organic } \\
\text { matter } \\
\%\end{array}$} \\
\hline & & $\begin{array}{l}\text { Satura- } \\
\text { tion } \\
0 \mathrm{kPa}\end{array}$ & \begin{tabular}{|c|} 
Field \\
capacity \\
$-10 \mathrm{kPa}$ \\
\end{tabular} & $\begin{array}{c}\text { Refill } \\
\text { point } \\
-100 \mathrm{kPa}\end{array}$ & $\begin{array}{c}\text { Clay } \\
\%\end{array}$ & $\begin{array}{c}\text { Silt } \\
\%\end{array}$ & $\begin{array}{c}\text { Sand } \\
\%\end{array}$ & & \\
\hline $0-150$ & 1508 & 0.402 & 0.292 & 0.233 & 36 & 23 & 41 & 2.1 & 3.3 \\
\hline $150-300$ & 1595 & 0.412 & 0.289 & 0.230 & 35 & 24 & 41 & 3.4 & 3.3 \\
\hline $300-450$ & 1604 & 0.394 & 0.294 & 0.241 & 33 & 27 & 40 & 15.3 & 2.9 \\
\hline $450-600$ & 1476 & 0.414 & 0.291 & 0.253 & 46 & 15 & 39 & 8.7 & 2.8 \\
\hline Mean & 1546 & 0.406 & 0.292 & 0.239 & 38 & 22 & 40 & 7.4 & 3.1 \\
\hline
\end{tabular}
(using the data-logger $5^{\text {th }}$ order polynomial instruction). The soil sensors were calibrated using undisturbed soil cores removed from the site. In the laboratory, the soil cores were saturated and the sensor voltage and the corresponding gravimetric soil-water 
content determined between saturation and air-dry conditions. Measurements were taken every two days to encompass a range of water contents while the samples were allowed to dry. After each voltage and soil-water content determination, the mass of the soil core was determined and the gravimetric soil-water content calculated. Linear regression was used to compare volumetric soil-water content estimated using the factory-supplied and soil-estimated parameters $a_{\mathrm{o}}$ and $a_{1}$ (Eqs. (2) and (3)) with the soil-water content determined in the laboratory.

The temperature dependence of the sensor voltage was determined by inserting the sensor and a close-contact thermocouple into a soil core of known soil-water content. The soil containers were covered with aluminium foil to reduce evaporation of water. The experiment was repeated for several soil cores for a range of known volumetric water contents prepared in the laboratory: $0.15,0.34$ and $0.42 \mathrm{~m}^{3} \cdot \mathrm{m}^{-3}$. Each sensor was artificially heated using a heater wire. Chromel-constantan thermocouples, in contact with the body of the sensors inserted into the soil, were used to measure the temperature variation of the sensor and soil.

To develop retentivity relationships for the field soil cores, the soil cores were saturated in the laboratory and subjected to various suctions on a porous tension table with a hanging column of water to study characteristics for matric potentials of 0 and $-10 \mathrm{kPa}$ (Avery and Bascomb, 1974). Retentivity characteristics at a matric potential of $-100 \mathrm{kPa}$ was determined using undisturbed soil cores and the pressure-plate apparatus (Soil Moisture Equipment Corp., Santa Barbara, California). The volumetric water contents for each soil-water potential was determined using the ThetaProbe. When necessary, soil cores were dried in an oven. Before replacing the cores on the porous plate for the next pressure equilibrium step, the plate was made wet to ensure good contact between ceramic plate, filter paper and soil. A detailed description of the equipment and procedures are found in Klute (1986). The matric potentials corresponding to field capacity and wilting point for these soils (Table 1) were those recommended by Schulze et al. (1985).

\section{Results and discussion}

Selected physical characteristics of the soil from the site are shown in Table 1 . Soil bulk density ranged from $1476 \mathrm{~kg} \cdot \mathrm{m}^{-3}$ (for the 400 to $500 \mathrm{~mm}$ soil layer) to $1604 \mathrm{~kg} \cdot \mathrm{m}^{-3}$ (300 to $450 \mathrm{~mm}$ layer) with an average of $1546 \mathrm{~kg} \cdot \mathrm{m}^{-3}$. Mean soil-water content at saturation measured using the pressure plate laboratory method was $0.406 \mathrm{~m}^{3} \cdot \mathrm{m}^{-3}$ and at $-10 \mathrm{kPa}$ was $0.292 \mathrm{~m}^{3} \cdot \mathrm{m}^{-3}$. Particle size distribution showed the soil to have a clay loam texture. The soil had a high gravel content of iron and manganese concretions in the 300 to $450 \mathrm{~mm}$ layer. The organic matter content averaged $3.1 \%$.

\section{Factory calibration vs. soil calibration}

The factory-supplied parameters for mineral soil, $a_{\mathrm{o}}=1.6$ and $a_{1}=8.4$, were used to estimate soil-water content (Eq. (2)). The average soil-estimated parameters of $a_{\mathrm{o}}=1.411$ and $a_{1}=11.09$ were used to estimate the soil-calibrated soil-water content. These parameters were calculated using Eqs. (1) and (3). The sensor output voltage under soil air-dry conditions was $0.074 \mathrm{~V}$ and under saturated conditions was $0.882 \mathrm{~V}$, while the soil-water content at saturation was $0.406 \mathrm{~m}^{3} \cdot \mathrm{m}^{-3}$. The dielectric constant of the dry and saturated soil was 2.1 and 23.1 (Eq. (3)), respectively.

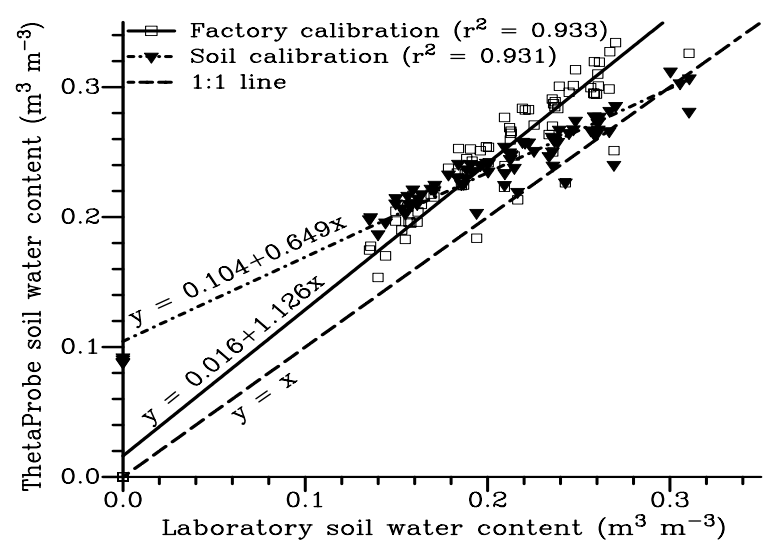

Figure 1

Laboratory calibration of the sensor soil-water content using the factory-supplied and the soil-estimated parameters vs. the laboratory soil-water content

The linear sensor calibration relationship for all soil depths is shown in Fig. 1 for soil samples removed from the study site. The linear regression statistics for $\theta_{v}$ determined using the factory-supplied or soil-estimated parameters $v s . \theta_{\mathrm{v}}$ determined gravimetrically at the various matric potentials for individual depths and total depth are shown in Table 2 . Unfortunately there was difficulty in measuring soil-water content between 0 and $0.15 \mathrm{~m}^{3} \cdot \mathrm{m}^{-3}$ because the sensor, in spite of its sharp rods, could not be forced into the hard soil without damage to the rods for these low soil-water contents. The 300 to $450 \mathrm{~mm}$ layer had the lowest coefficient of determination $r^{2}$ (Table 2) probably due to the presence of the coarse lateritic material. Iron-rich minerals have been reported by Robinson et al. (1994) to affect the apparent dielectric constant measurement using the TDR technique for soil-water measurement. However, analysis of the 95\% confidence limits showed that there were no significant differences in the slope and intercept values between different layers. It was therefore decided to pool the data from all depths between 0 and $600 \mathrm{~mm}$ and use one regression relationship.

There was a somewhat improved correlation of soil-water content estimates when the factory-supplied parameters were used compared to when using the soil-estimated parameters. There was a significant difference between the slope values as judged by the confidence interval for the various depths (Table 2). Soil variability with depth and sampling error may be the main causes for this discrepancy. These causes may also explain the difference between the calibration parameters for the different depths. On average, $\theta_{\mathrm{v}}$ could be estimated to within 0.036 $\mathrm{m}^{3} \cdot \mathrm{m}^{-3}$ when using the soil-estimated parameters and 0.034 $\mathrm{m}^{3} \cdot \mathrm{m}^{-3}$ when using the factory-supplied parameters. Both the soil and the factory calibrations gave smaller errors compared to the maximum error of $0.050 \mathrm{~m}^{3} \cdot \mathrm{m}^{-3}$ specified by the manufacturer. The standard deviation for volumetric water content of $0.021 \mathrm{~m}^{3} \cdot \mathrm{m}^{-3}$ (factory-calibration) and $0.013 \mathrm{~m}^{3} \cdot \mathrm{m}^{-3}$ (soilcalibration) was within the range of 0.005 to $0.023 \mathrm{~m}^{3} \cdot \mathrm{m}^{-3}$ found by Jacobson and Schjonning (1993a) using a TDR technique. The soil calibration was determined from the ThetaProbe voltage with the probe inserted into dry soil so as to determine $a_{\mathrm{o}}=\sqrt{\varepsilon_{0}}$ and then inserted into wet soil so as to determine the square root of the dielectric constant for saturated soil $\sqrt{ } \varepsilon_{w}$ (Eq. 1). The $a_{1}$ value was then determined using Eq. (3). The estimated parameters were $a_{\mathrm{o}}=1.411$ and $a_{1}=11.09$ for the Tala Valley soil. 


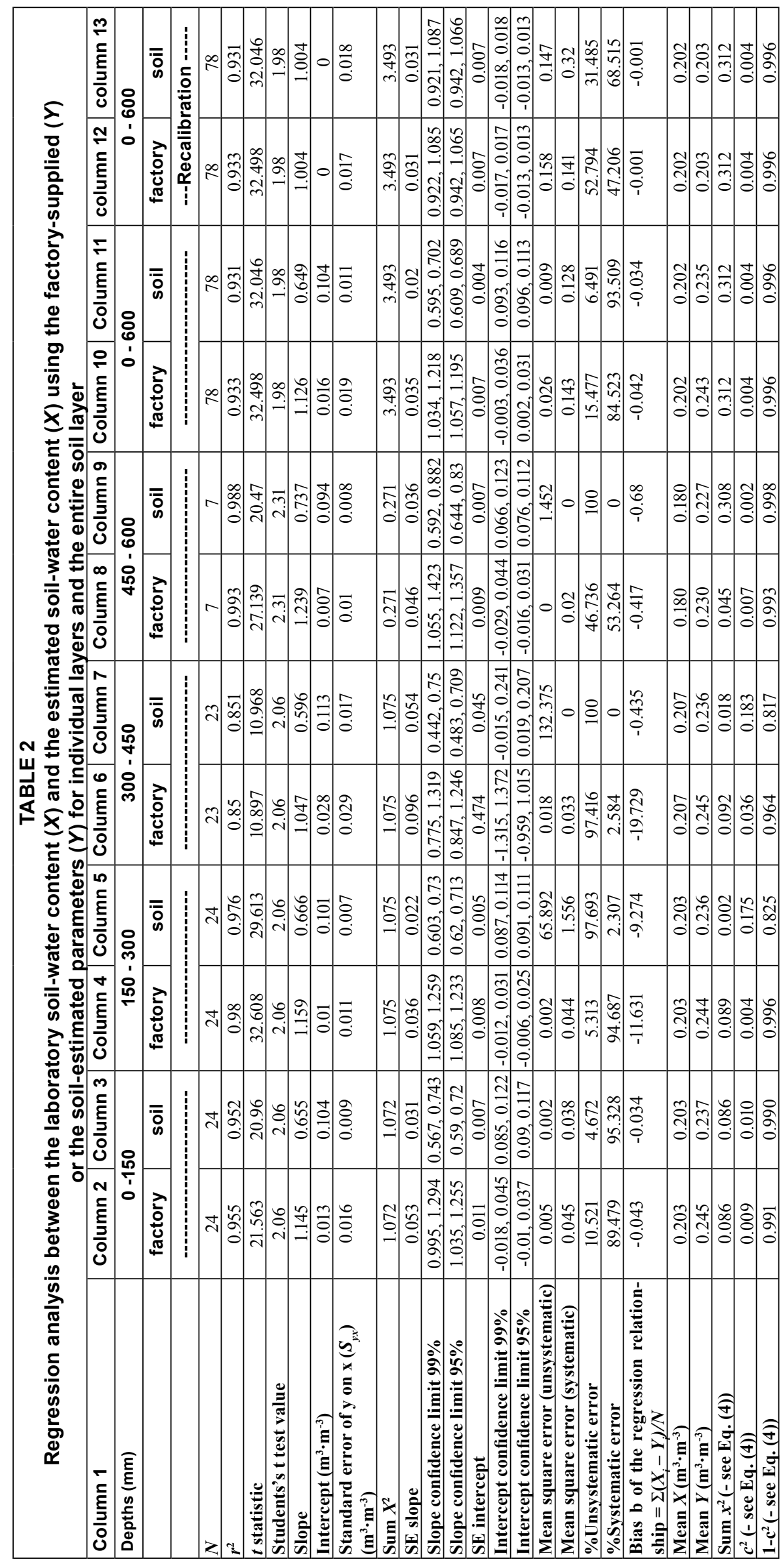

There was a slight overestimation of soil-water content when using the factory-supplied calibration factors compared to the laboratory-determined soil-water content. Little et al. (1998) found that soil-water content was underestimated for a ThetaProbe in a clay soil. Standard deviations for the slope and intercept for the present study were smaller that those obtained in the mentioned reference. In the present study an $r^{2}$ of 0.92 was obtained compared to an $r^{2}$ of 0.76 in an Inanda soil (clay texture) and 0.92 in a Hutton soil (sandy texture) obtained in KwaZulu-Natal by Little et al. (1998).

The estimate of the soil-water content indices (saturation, air entry, field capacity, refill point and wilting point) using the sensor and related percentage errors for the factory-supplied and soil-estimated parameters is shown in Fig. 2. For each depth, the sample water contents were averaged but for Case 5 in Fig. 2, the average was for all samples at all depths. The soil-water content at air entry $(-5 \mathrm{kPa})$ was determined as reported by Gregson et al. (1987), Williams et al. (1992) and Williams and Ahuja (1993). Other soil-water content indices were measured on undisturbed soil using the porous tensions table or pressure plate laboratory methods. Both the factory-supplied and the soil-estimated parameters resulted in an average error of more than $20 \%$.

\section{Recalibration of the sensor}

An attempt was made to recalibrate the sensors (see Eq. (4) and the statistics from Table 2 (Columns 10 and 11)) in order to improve the regression (Columns 12 and 13). The regression line was forced through the $(0,0)$ origin based on the assumption that if the soil-water content is $0 \mathrm{~m}^{3} \cdot \mathrm{m}^{-3}$, then the measured value would also be $0 \mathrm{~m}^{3} \cdot \mathrm{m}^{-3}$. The range of soil-water contents was limited to greater than about $0.150 \mathrm{~m}^{3} \cdot \mathrm{m}^{-3}$ since below this value, as mentioned previously, the soil was too hard to insert the sensor. The slope, $y$-intercept and bias of the recalibrated sensors were closer to the ideal slope of 1 , and $y$-intercept and bias of 0 . The $r^{2}$ was much the same, while the standard error of the predicted $Y$ values for each $X$ value increased for both the factory and the soil calibration. Using the recalibration procedure, soil-water con- 


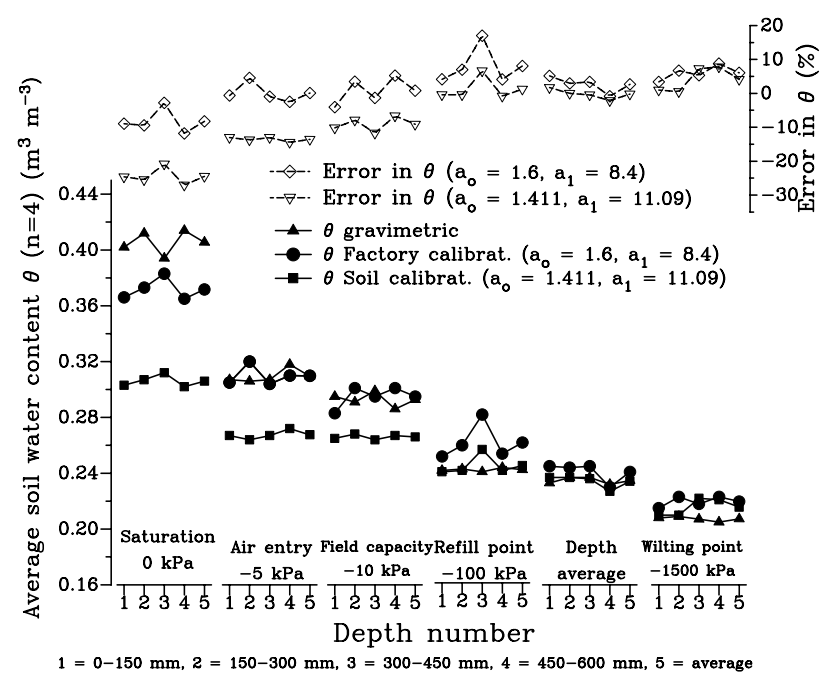

Figure 2

The estimated soil-water content indices using the sensor with the factory-supplied $\left(a_{0}=1.6\right.$ and $\left.a_{1}=8.4\right)$ and soil-estimated $\left(a_{0}\right.$ $=1.411$ and $a_{1}=11.09$ ) parameters, and the corresponding error

tent could be estimated to within $0.020 \mathrm{~m}^{3} \cdot \mathrm{m}^{-3}$ for both the soilestimated and the factory-supplied parameters. There was an improvement for the soil-estimated parameters. The estimated percentage errors for different soil-water content indices after the recalibration process are presented in Fig. 3 with the adjustment of the factory-supplied parameters $\left(a_{\mathrm{o}}=1.82\right.$ and $\left.a_{1}=7.83\right)$ and adjustment of the soil-estimated parameters $\left(a_{0}=1.83\right.$ and $a_{1}$ $=7.33$ ) and the corresponding error. Compared to the percentage error shown in Fig. 2, the errors for both the factory-supplied and the soil-estimated parameters decreased.

The "best fit" expression for estimating soil-water content using the sensor was obtained using a recalibration procedure (Snedecor and Cochran, 1980). This procedure, based on Eq. (4), allowed the laboratory soil-water content to be estimated $\left(\theta_{v-\text { adiust }}\right.$, the $X$-value) using:

- The estimated $\theta_{\mathrm{v}}$ determined using the sensor ( $Y$-value $)$

- The slope $b=0.872$ and the intercept $I=0.037 \mathrm{~m}^{3} \cdot \mathrm{m}^{-3}$ (Eq. 4) obtained from the regression between soil-water content determined using the sensor- and laboratory-measured soil-water content (Table 2, Column 10)

- A factor $c^{2}=\left(1 / x^{2}\right)\left(t \mathrm{~S}_{\mathrm{yx}} / b\right)^{2}=0.0046$ (Table 2, Column 10) which takes into account the standard error of $Y$ on $X$, the Student $t$ statistic and the sum of the deviation squared $\left(x^{2}\right)$ of the laboratory soil-water content from the average (Eq. (4)), where:

$$
\theta_{\mathrm{v} \text {-adjust }}=\left[\left(\theta_{\mathrm{v}}-I\right) / b\right] /\left(1-c^{2}\right) \text {. }
$$

A regression between the $\theta_{\mathrm{v} \text {-adjust }}(X)$ and $\sqrt{\varepsilon}(Y)$ gave a $y$-intercept of 1.83 and a slope of 7.82 . The $y$-intercept and slope of the regression between $\theta_{\mathrm{v} \text {-adjust }}(X)$ and $\sqrt{\varepsilon}(Y)$ corresponded to $a_{\mathrm{o}}=1.83$ and $a_{1}=7.82$ for the calibration constants (see Eq. (2)) compared to the values $a_{0}=1.6$ and $a_{1}=8.4$ provided by the manufacturer. The values $a_{\mathrm{o}}=1.83$ and $a_{1}=7.33$ were obtained for the $\theta_{\mathrm{v} \text {-adjust }}$ adjusted for the soil-estimated parameters. Use of calibration constants $a_{\mathrm{o}}=1.83$ and $a_{1}=7.82$ or $a_{\mathrm{o}}=1.83$ and $a_{1}=$ 7.33 would produce the statistics shown in Table 2 (Columns 12 and 13). Comparison of $\theta_{v \text {-adjust }}$ and $\theta_{v}$ values determined in the laboratory is shown in Fig. 4 . The $\theta_{\text {vadjust }}$ approached the 1:1 line when using $a_{\mathrm{o}}=1.83$ and $a_{1}=7.82$ than when using factory-supplied parameters for which $a_{\mathrm{o}}=1.6$ and $a_{1}=8.4$ (Fig. 1).

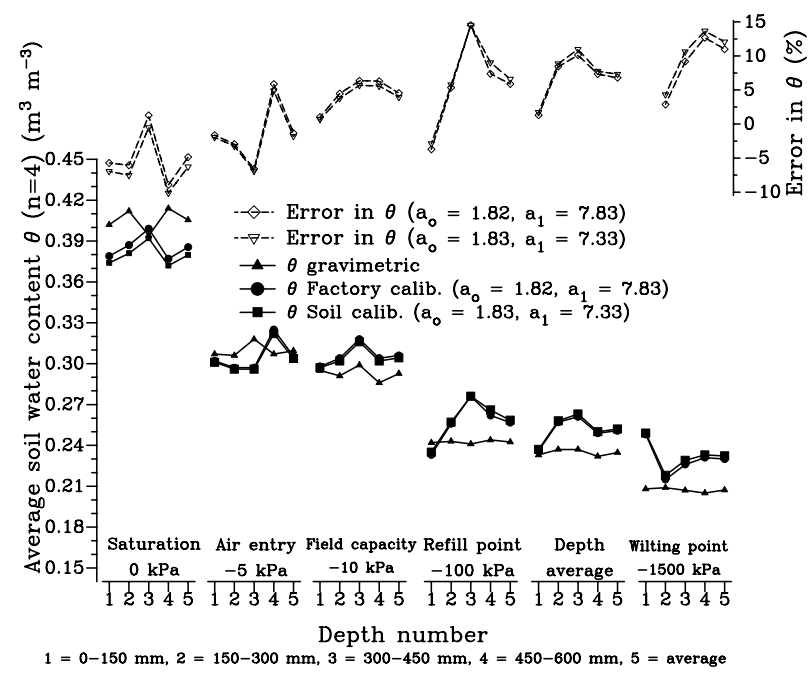

Figure 3

The estimated soil-water content indices using the recalibration of the sensor

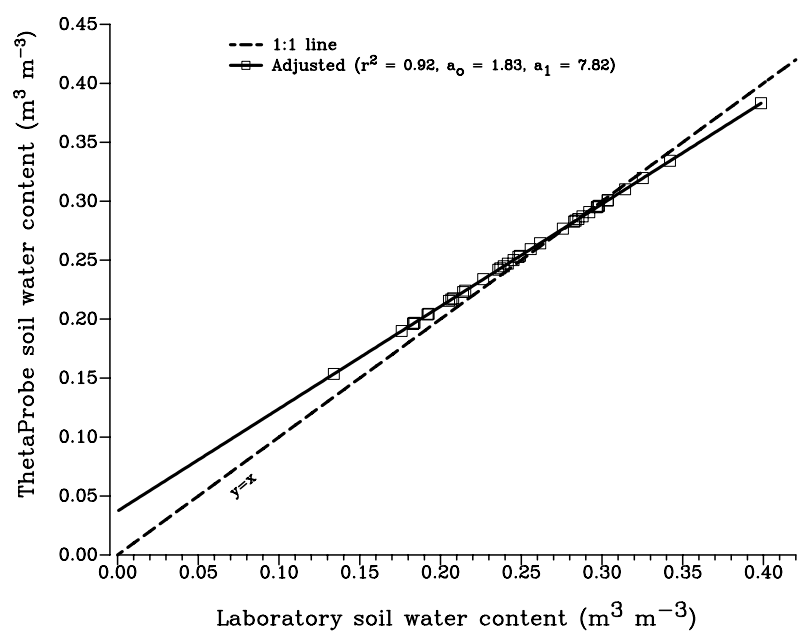

Figure 4

Comparison of $\theta_{v \text {-adjus }}\left(y\right.$-axis) and $\theta_{v}(x$-axis $)$ determined in the laboratory

\section{Effect of soil temperature, bulk density and texture on sensor measurements}

The error in soil-water content due to a temperature variation of between 12 and $18^{\circ} \mathrm{C}$ was not more than $0.015 \mathrm{~m}^{3} \cdot \mathrm{m}^{-3}$ for the surface soil layers and not more than $0.005 \mathrm{~m}^{3} \cdot \mathrm{m}^{-3}$ for the deeper layers. Topp et al. (1980) also had satisfactory results for temperatures between 10 and $30^{\circ} \mathrm{C}$. In this experiment, soil-water contents were estimated accurately for soil layers with a high clay content and relatively low soil bulk density (Tables 1 and 2). The $r^{2}$ of the linear regression between the sensor-estimated soil-water content $(Y)$ and the laboratory soil-water content $(X)$ was 0.920 for the adjusted calibrations (Fig. 4). Combining bulk density or clay content with the laboratory soil-water content ( $X_{1}$ and $X_{2}$ ) increased $r^{2}$ to 0.921 (data not shown). Combining the bulk density and clay content with the laboratory soil-water content $\left(X_{1}, X_{2}\right.$ and $\left.X_{3}\right)$ increased $r^{2}$ to 0.927 . The change in the soil bulk density and clay content of different layers therefore had a very small effect on the sensor-determined soil-water content. In the present study, the range of soil bulk density and clay content were relatively narrow and the results are therefore not 
sufficiently conclusive. Thus, the possibility of including bulk density and clay content into the calibration (Eqs. (1) and (2)) was not pursued further for these soils. Similar conclusions were reached by Topp et al. (1980) and Jacobson and Schjonning (1993b) for a TDR method using soil samples that included a wider textural and bulk density range than those used in this experiment. However, it is recommended that more research be done on the effect of the bulk density, texture, temperature and other soil physical characteristics on the estimates of the dielectric constant of the soil.

\section{Conclusions}

There was a relatively better performance of the FDR sensor used in estimating soil-water content when using the factorysupplied parameters than when using the soil-estimated parameters. A slope of 1 , and an intercept and bias of zero were obtained for both the factory-supplied and the soil-estimated parameters when a recalibration process was used. Therefore the sensor could be used with confidence to monitor soil-water content for irrigation or hydrological purposes. For the clay loam soil used, the clay content, soil bulk density and temperature effects on the sensor voltage showed a negligible influence on the measured soil-water content. As judged by the increased variation in the measured soil-water content in the 300 to $450 \mathrm{~mm}$ layer, the coarse structure and the presence of iron in a laterite layer affected sensor performance. Volumetric soil-water content could be measured to within $0.020 \mathrm{~m}^{3} \cdot \mathrm{m}^{-3}$.

\section{Acknowledgments}

We acknowledge the assistance of the late Professor MA Johnston (Soil Science, University of Natal) in the initial phases of this work. The co-operation of Mr ME Wild and his son Alex of the Vita Fresh Farm (Tala Valley) and use of facilities is gratefully acknowledged. We acknowledge the financial support of the Deutscher Akademischer Austauschdienst (DAAD) (Germany), National Research Foundation, Water Research Commission and the University of KwaZulu-Natal. The authors also acknowledge the A. Neto University (Angola) for encouragement. We express our gratitude to the following scientists and technicians for their co-operation and assistance: Dr CS Everson, Professor EA Ripley, Mr PN Dovey and Ms J Manickum. Our thanks go to Mrs MA Savage for editorial assistance.

\section{References}

AVERY BW and BASCOMB CL (1982) Soil Survey Laboratory Methods. Soil Survey. Technical Monograph No. 6. Harpenden, UK. 83 pp.

BLAKE GR and HARTGE KH (1986) Bulk density. In: Campbell, GS, Jackson RD, Mortland MM, Nielsen DR and Klute A (eds.) Methods of Soil Analysis. Part 1:Physical and Mineralogical Methods. Agronomy Monograph No. 9 (2nd edn.) Am. Soc. Agron. Inc., Madison, Wisconsin, USA. 363-376.

CZARNOMSKI NM, MOORE GW, PYPKER TG, LICATA J and BOND BJ (2005) Precision and accuracy of three alternative instruments for measuring soil water content in two forest soils of the Pacific Northwest. Can. J. For. Res. 35 1867-1876.

DELTA-T DEVICES (1999) ThetaProbe Soil Moisture Sensor User Manual. Delta-T Devices, Cambridge, UK.

DRNEVICH VP, ASHMAWY AK, YU X and SALLAM AM (2005) Time domain reflectometry for water content and density of soils: study of soil-dependent calibration constants. Can. Geotech. J. $\mathbf{4 2}$ 1053-1065.
EVETT SR, HOWELL TA and TOLK JA (2005) Time domain reflectometry laboratory calibration in travel time, bulk electrical conductivity, and effective frequency. Vadose Zone J. 4 1020-1029.

GEE GW and BAUDER JW (1986) Particle-size analysis. In: Campbell GS, Jackson RD, Mortland MM, Nielsen DR and Klute A (eds.) Methods of Soil Analysis. Part 1: Physical and Mineralogical Methods. Agronomy Monograph No. 9 (2nd edn.) Madison, Wisconsin, USA. 383-409.

GEBREGIORGIS MF and SAVAGE MJ (2006a) Determination of the timing and amount of irrigation of winter cover crops with the use of dielectric constant and capacitance soil water content profile methods. S. Afr. J. Plant Soil $\mathbf{2 3}$ (In press).

GEBREGIORGIS MF and SAVAGE MJ (2006b) Field, laboratory and estimated soil-water content limits. Water $S A$ (In press).

GREGSON K, HECTOR DJ and McGOWAN M (1987) A one-parameter model for the soil water characteristic. J. Soil Sci. 38 483-486.

GROVES SJ, ROSE SC (2004) Calibration equations for Diviner 2000 capacitance measurements of volumetric soil water content of six soils. Soil Use Mgt. 20 96-97.

JACOBSON OH and SCHJONNING P (1993a) A laboratory calibration of time domain reflectometry for soil water measurement including effects of bulk density and texture. J. Hydrol. 151 147-157.

JACOBSON OH and SCHJONNING P (1993b) Field evaluation of time domain reflectometry for soil-water measurements. J. Hydrol. 151 159-172.

KLUTE A (1986) Water retention: Laboratory methods. In Campbell GS, Jackson RD, Mortland MM, Nielsen DR and Klute A (eds.) Methods of Soil Analysis. Part 1: Physical and Mineralogical Methods. Agronomy Monograph No. 9 (2nd edn.). Am. Soc. Agron. Inc., Madison, Wisconsin, USA. 383-409.

LITTLE KM, METELERKAMP B and SMITH CW (1998) A comparison of three methods of soil-water content determination. S. Afr. J. Plant Soil 15 80-89.

LUKANGU G, SAVAGE MJ and JOHNSTON MA (1999) Use of subhourly soil water content measured with a frequency-domain reflectometer to schedule irrigation of cabbages. Irrig. Sci. 19 7-13.

MIYAMOTO T and MARUYAMA A (2004) Dielectric coated water content reflectometer for improved monitoring of near surface soil moisture in heavily fertilized paddy field. Agric. Water Mgt. 64 161168.

MWALE SS, AZAM-ALI SN and SPARKES DL (2005) Can the PR1 capacitance probe replace the neutron probe for routine soil-water measurement? Soil Use Mgt. 21 340-347.

ROBINSON DA, BELL JP and BATCHELOR CH (1994) Influence of iron minerals on the determinations of soil water content using dielectric techniques. J. Hydrol. 161 169-180.

ROTH K, SCHULIN R, FLUHER H and ATTINGER W (1990) Calibration of time domain reflectometry for water content measurement using a composite dielectric approach. Water Resour. Res. 26 2267-2273.

SCHULZE RE, HUTSON JL and CASS A (1985) Hydrological characteristics and properties of soil in Southern Africa 2. Soil water retention models. Water SA 11 129-136.

SNEDECOR GW and COCHRAN WG (1980) Statistical Methods (7th edn.). The Iowa State University Press, Ames, Iowa, USA.

TOPP GC, DAVIS JL and ANNAN AP (1980) Electromagnetic determination of soil water content measurement in coaxial transmission lines. Water Resour. Res. 16 574-582.

WHALLEY WR, COPE RE, NICHOLL CJ and WHITMORE AP (2004) In-field calibration of a dielectric soil moisture meter designed for use in an access tube. Soil Use Mgt. 20 203-206.

WILLIAMS RD and AHUJA LR (1993) Using available water content with the one-parameter model to estimate soil water retention. Soil Sci. 156 380-388.

WILLIAMS RD, AHUJA LR and NANEY JW (1992) Comparison of method to estimate soil water characteristic from soil texture, bulk density, and limited data. Soil Sci. 153 172-184.

WYSEURE GCL, MOJID MA and MALIK MA (1997) Measurement of volumetric water content by TDR in saline soils. Euro. J. Soil Sci. 48 347-354. 